\title{
The response of the hepatic insulin-like growth factor system to growth hormone and dexamethasone in calves
}

\author{
H M Hammon, Y Zbinden, H Sauerwein ${ }^{1}$, B H Breier ${ }^{2}$, J W Blum \\ and $\mathbf{S} \mathbf{S}$ Donkin ${ }^{3}$ \\ Division of Animal Nutrition and Physiology, Institute of Animal Genetics, Nutrition and Housing, Faculty of Veterinary Medicine, University of Berne, \\ Bremgartenstr. 109a, CH-3012 Berne, Switzerland \\ ${ }^{1}$ Institute of Physiology, Biochemistry and Animal Hygiene, University of Bonn, Germany \\ ${ }^{2}$ Liggins Institute for Medical Research, Faculty of Medical and Health Science, University of Auckland, Private Bag 92019, Auckland, New Zealand \\ ${ }^{3}$ Department of Animal Science, Purdue University, West Lafayette, Indiana 47906, USA \\ (Requests for offprints should be addressed to H M Hammon; Email: harald.hammon@itz.unibe.ch)
}

\begin{abstract}
Glucocorticoids inhibit postnatal growth and yet can stimulate the somatotropic axis around birth. The aim of the present study was to investigate the effects of dexamethasone on the somatotropic axis and on the responses of the insulin-like growth factor (IGF) system to growth hormone treatment in calves. Calves $(n=24)$ were randomly divided into four groups. Group DX was injected with dexamethasone $(30 \mu \mathrm{g} / \mathrm{kg}$ body weight per day), group GH was injected with $500 \mathrm{mg}$ slow-release bovine growth hormone at 14-day intervals, group GHDX was injected with dexamethasone and bovine growth hormone, and group CNTRL (serving as control) was injected with saline from day 3 to day 42 of life. Blood samples were taken on day 3 and blood and liver samples were obtained on days 7, 14, 28 and 42. Body weight increased in the CNTRL and GH groups up to the end of the study and in the DX and GHDX groups up to the fourth week. Dexamethasone treatment decreased $(P<0 \cdot 05)$ plasma IGF binding protein (IGFBP)-1 on days 7 and 14 , but increased $(P<0 \cdot 05)$ plasma IGFBP-1, decreased $(P<0 \cdot 05)$ plasma IGF-I and IGFBP-3, and
\end{abstract}

decreased hepatic mRNA for growth hormone receptor (GHR) and IGF-I on day 42. Growth hormone treatment increased $(P<0 \cdot 05)$ plasma growth hormone concentrations on days 7 and 14 , tended to increase $(P<0 \cdot 1)$ plasma IGF-I concentrations on day 42 , and increased $(P<0 \cdot 05)$ hepatic mRNA levels of GHR on day 14 and IGF-I mRNA levels on days 7 and 14. The combined dexamethasone and growth hormone treatment increased plasma growth hormone concentrations on day 7 and resulted in the highest plasma concentrations of IGF-I and IGFBP-3 (day 7 to day 28) as well as the greatest abundance of hepatic GHR (day 14) and IGF-I (days 7 and 14) mRNA. Plasma IGFBP-1 concentrations in the GHDX group behaved in a similar manner as in the DX group. In conclusion, the response of the somatotropic axis to growth hormone treatment could be greatly enhanced by dexamethasone treatment during the neonatal and early postnatal period, but body weight gain was not improved. Dexamethasone alone inhibited the somatotropic axis and postnatal growth after the first month of life.

Journal of Endocrinology (2003) 179, 427-435

\section{Introduction}

Although several hormones regulate postnatal growth, the somatotropic axis becomes the dominant endocrine system (Spencer 1985, Etherton \& Bauman 1998, Breier et al. 2000). Glucocorticoids inhibit prenatal (Newnham \& Moss 2001) and postnatal growth, in part by direct interaction with the somatotropic axis (Spencer 1985, Unterman \& Phillips 1985, Bloomfield et al. 2001, Butler \& LeRoith 2001, Renaville et al. 2002). However, in the perinatal period glucocorticoids are supposed to enhance the maturation of the somatotropic axis. The prepartum cortisol surge plays an important role in initiating the perinatal switch of the somatotropic axis from the fetal to the postnatal status and function (Gluckman et al. 1999, Breier et al. 2000). Thus, cortisol stimulates hepatic growth hormone receptor (GHR) and insulin-like growth factor-I (IGF-I) mRNA levels in the sheep fetus (Li et al. 1996) and studies with hepatocytes indicated an increase in GHR and IGF-I expression and enhanced IGF-I response to growth hormone if combined with dexamethasone administration (Brameld et al. 1995). Recent studies in neonatal pigs report even enhanced postnatal growth and stimulation of the growth hormone (GH)-IGF system after dexamethasone treatment, lasting in part for the whole growth period (Carroll 2001, Gaines et al. 2002). 
In addition, our own investigations in neonatal calves indicated a similar effect of dexamethasone on the somatotropic axis (Sauter et al. 2003). In contrast, dexamethasone reduced IGF-I levels in adult cattle (Elsasser et al. 1997, Maciel et al. 2001). Therefore, the effects of glucocorticoids on the somatotropic axis are inconsistent and may depend on the developmental stage.

Little is known of how glucocorticoids interfere with the somatotropic axis in the early growth period of calves. Furthermore, the effects of glucocorticoid treatment on growth in fetal animals and preterm infants are inconsistent (Newnham \& Moss 2001). Plasma cortisol concentrations in calves were high around birth and then rapidly decreased with postnatal growth, whereas IGF-I concentrations decreased during the first week of life, but then increased (Kerr et al. 1991, Hammon \& Blum 1997, 1998, Nussbaum et al. 2002). The present study was carried out to clarify the influence of dexamethasone on the somatotropic axis during the first 6 weeks of life. We have tested the hypothesis that dexamethasone treatment modifies the somatotropic axis and the response of the hepatic IGF system to growth hormone treatment in calves. Therefore, we have treated calves for 40 days with either dexamethasone or growth hormone alone or in combination.

\section{Materials and Methods}

\section{Animals, husbandry, feeding and experimental procedures}

All animal handling procedures were approved by the Purdue Animal Care and Use Committee. Twenty-four male Holstein calves, aged 1-2 days, were purchased from a single large commercial dairy farm and transported to the Purdue University Dairy Research and Education Center. Calves were born spontaneously, separated from their dams at birth, fed colostrum and housed individually. Calves were weighed upon receipt, blocked by initial body weight and randomly assigned within each block to one of four treatment groups ( $n=6$ per group). The following treatments were initiated on day 3 of life: dexamethasone was administered subcutaneously (Azium, Schering-Plough, Terre Haute, IN, USA) at $30 \mu \mathrm{g} / \mathrm{kg}$ body weight per day (group DX); growth hormone, as $500 \mathrm{mg}$ slow-release recombinant bovine somatotropin (Posilac, Monsanto, St Louis, MO, USA), was administered subcutaneously at 14-day intervals (on days 3, 17 and 31 of age; group $\mathrm{GH}$ ); dexamethasone and Posilac (group GHDX) were administered in combination at the same concentrations as for the DX and GH groups and were injected subcutaneously; saline treatment acted as a control (group CNTRL). Treatments continued until 42 days of age. The dose of dexamethasone was chosen according to previous studies with neonatal calves (Sauter et al. 2003). The dose of bovine somatotropin is based on Holzer et al. (2000) and previous studies using neonatal calves
(Hammon \& Blum 1997). A constant rate of growth hormone release during the 14-day period was assumed to provide 0.5 to $0.9 \mathrm{mg} / \mathrm{kg}$ body weight per day, which is comparable to the effective daily injection of growth hormone used in previous studies (Hammon \& Blum 1997).

Calves were fed a milk replacer diet (Milk Specialties Company, Dundee, IL, USA), which contained 29\% crude protein, $15 \%$ crude fat and less than $0 \cdot 15 \%$ crude fiber at a rate of $2 \%$ of body weight on a dry milk replacer basis. Milk replacer was diluted with warm water to $15 \%$ solids and was fed in buckets twice daily at 0700 and at $1600 \mathrm{~h}$. Calves were weighed weekly, and the amount fed was adjusted according to body weight. Fresh water was available at all times. Calves that failed voluntarily to consume milk replacer within 45 min were fed their scheduled allotment of milk replacer via stomach tube.

To protect against bacterial infections all calves were injected intramuscularly with $1.5 \mathrm{mg} / \mathrm{kg}$ body weight ampicillin twice daily (Polyflex; Wyeth, Fort Dodge Animal Health, Overland Park, KA, USA) and 1500 $\mathrm{U} / \mathrm{kg}$ body weight penicillin $\mathrm{G}$ procaine daily (Penicillin G Procaine, G.C. Hanford, Syracuse, NY, USA) upon receipt and for the following 2 days. The health status was evaluated weekly based on the following clinical traits: rectal temperature, heart rate, respiratory rate, behavior, nasal discharge, respiratory sounds, appetite, fecal consistency and navel adspection. Calves with symptoms of respiratory or gastrointestinal infections were treated as per instructions of the Veterinary School at Purdue University.

\section{Blood sampling and analyses}

Blood was taken from the jugular vein with evacuated tubes on days $3,7,14,28$ and 42 of life. Tubes were put on crushed ice until centrifuged at $550 \mathrm{~g}$ for $15 \mathrm{~min}$. Supernatants were aliquoted and stored at $-20{ }^{\circ} \mathrm{C}$. Tubes containing dipotassium-EDTA $(1.8 \mathrm{~g} / 1$ blood $)$ were used for the determination of plasma concentrations of $\mathrm{GH}$, IGF-I, IGF binding protein (IGFBP)-1 and IGFBP-3 four to five hours after food intake. Plasma IGF-I, GH and IGFBP-1 concentrations were measured by radioimmunoassays as described previously (Hammon \& Blum 1997, Kaufhold et al. 2000). Plasma concentrations of IGFBP-3 were measured by enzyme immunoassay (EIA) as described by Hennies and Sauerwein (2003).

\section{Analyses in liver}

Liver biopsy samples (about $500 \mathrm{mg}$ ) were obtained on days 7, 14, 28 and 42 of life, 2 to $3 \mathrm{~h}$ after food intake for analysis of IGF-I and GHR mRNA. The biopsy technique was adapted from Greenfield et al. (2000). Calves were restrained using a small animal squeeze chute and tilt table combination and were placed on their left side. The area above the 11th and 12th intercostal space on a line 
from the hip joint to the elbow was clipped, scrubbed with Betadine (Purdue Pharma L.P., Stamford, CT, USA) and swabbed with $70 \%$ ethanol. Lidocaine $(10 \mathrm{ml} ; 2 \%$ lidocaine hydrochloride; Phoenix Pharmaceutical, St Joseph, MO, USA) was injected subcutaneously. Liver biopsy samples were obtained pericutaneously. Samples were rinsed in saline and transferred to a fresh tube containing a guanidinium thiocyanate solution (4 M guanidinium thiocyanate, $25 \mathrm{mM}$ sodium citrate ( $\mathrm{pH} 7 \cdot 4$ ), $0.5 \%$ sarkosyl and $0.1 \mathrm{M} \beta$-mercaptoethanol) and frozen in liquid nitrogen. All samples were stored at $-80^{\circ} \mathrm{C}$ until analysis.

\section{Isolation of RNA and Northern blotting}

Total RNA was extracted from biopsy samples and $20 \mu \mathrm{g}$ were separated by electrophoresis through a $1 \%$ agarose gel and transferred to a Genescreen membrane (NEN Life Science Products, Boston, MA, USA) and prehybridized as described (Donkin et al. 1996). The cDNA probes for GHR (total GHR) and IGF-I were kindly provided by Dr Matt Lucy (University of Missouri, MO, USA) and have been described recently (Kobayashi et al. 1999). The ${ }^{32} \mathrm{P}-$ labeled cDNA probes were prepared using ${ }^{32} \mathrm{P}[\mathrm{d}-$ CTP] and the Ready-to-Go DNA labeling beads dCTP random oligonucleotide priming kit (Pharmacia, Piscataway, NY, USA) to a specific activity of approxi-

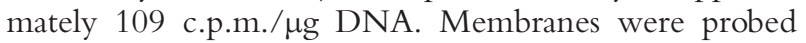
sequentially for IGF-I, GHR and $18 \mathrm{~S}$ rRNA. Membranes were exposed to Kodak X-Omat film for 1 to 3 days at $-80{ }^{\circ} \mathrm{C}$. Labeled probes were stripped by boiling for 60 min in a buffer containing 1\% sodium dodecyl sulfate, $15 \mathrm{mM}$ sodium chloride and $1.5 \mathrm{mM}$ sodium citrate. The removal of labeled probes from membranes was verified using a Geiger counter. Abundance of mRNA for each transcript was quantified from digital scans of autoradiographic images using Kodak Digital Science 1D Image Analysis software (Eastman Kodak Co, Rochester, NY, USA). Differences in loading and transfer of RNA among samples were adjusted by normalizing the GHR and IGF-I data for each calf to the corresponding intensity of the $18 \mathrm{~S}$ signal for each sample. A pooled RNA sample was used for correction between blots. The size of the transcript was determined by the migration distance relative to RNA standards. Northern blots of GHR and IGF-I resulted in one single band at $4.2 \mathrm{~kb}$ for GHR and $7 \cdot 5 \mathrm{~kb}$ for IGF-I and were supported by findings by others (Vandehaar et al. 1995).

\section{Statistical procedures}

Values of body weight, feed intake, blood traits and mRNA were expressed as means \pm S.E.M. and the data were evaluated using the RANDOM and REPEATED methods of the MIXED procedure (SAS 1995). The procedure analyses of repeated measurements considers

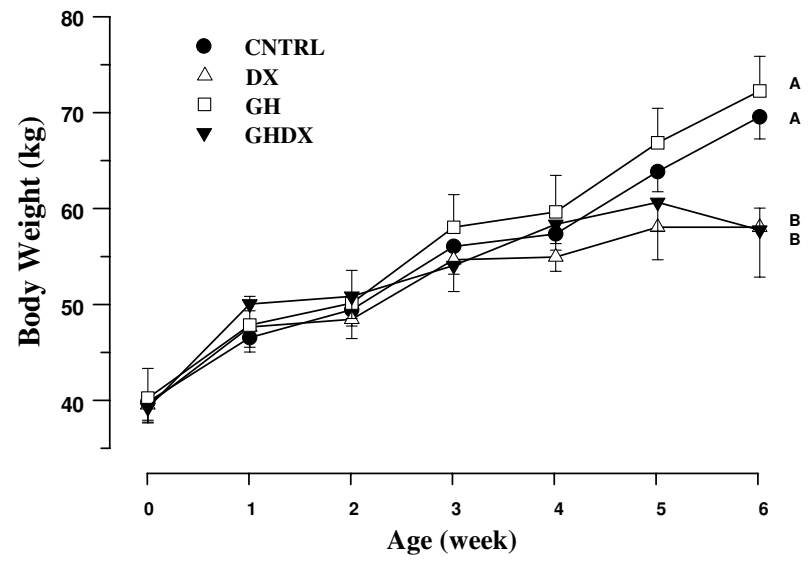

Figure 1 Body weight during the experimental period in control calves (CNTRL), calves treated with dexamethasone $(30 \mu \mathrm{g} / \mathrm{kg}$ body weight/day; DX), calves treated with growth hormone (500 mg/14 days; GH), and calves treated with dexamethasone and growth hormone (GHDX) in the same amounts as the DX and $\mathrm{GH}$ groups. Means with different uppercase letters $(\mathrm{A}, \mathrm{B})$ are significantly different $(P<0.05)$ at the specific time points.

random effects in the statistical model and permits modeling of the covariance structure of the data. Dexamethasone, growth hormone treatment and time were fixed effects and the individual calves were considered random effects. For the evaluation of differences in time-dependent changes within dexamethasone or growth hormone treatments, interactions (dexamethasone $\times$ time; growth hormone $\times$ time) were included in the model. Treatment and time effects were localized by Bonferroni $t$-test $(P<0 \cdot 05)$. Due to heteroscedasticity of IGFBP-1, the data were transformed to $\log$ values prior to analysis, and the reported values reflect the untransformed means.

\section{Results}

Food intake, body weight and health status

Body weight (Fig. 1) increased $(P<0.05)$ in the CNTRL and GH groups up to week 6 and in the DX and GHDX groups up to week 5. Different treatments affected $(P<0 \cdot 05)$ body weight with time. Calves of the DX and GHDX groups ceased growing after week 4 of life, and in week 6 body weight was higher $(P<0.05)$ in the CNTRL and GH groups than in the DX and GHDX groups. Food intake increased in accordance with body weight in all groups from $5 \cdot 3 \pm 0 \cdot 3$ to $8 \cdot 6 \pm 0 \cdot 4 \mathrm{~kg}$ milk per day from week 1 to week 6 . Food intake was influenced differently $(P<0.05)$ by different treatments during the experimental period and was reduced $(P<0 \cdot 05)$ in week 6 by dexamethasone treatment $(8 \pm 0 \cdot 5$ and $9 \cdot 2 \pm 0 \cdot 3 \mathrm{~kg}$ milk per day for dexamethasone-treated and non-dexamethasonetreated calves respectively). Two calves from the DX and GHDX groups respectively were excluded from the study 


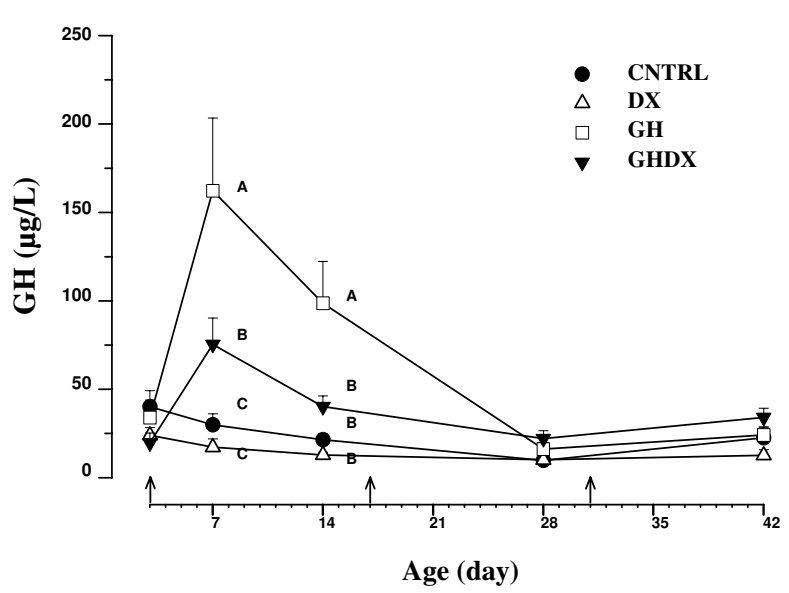

Figure 2 Plasma growth hormone $(\mathrm{GH})$ concentrations on days 3, $7,14,28,42$ of life in control calves (CNTRL), calves treated with dexamethasone (30 $\mu \mathrm{g} / \mathrm{kg}$ body weight/day; DX), calves treated with growth hormone (500 mg/14 days; $\mathrm{GH}$ ), and calves treated with dexamethasone and growth hormone (GHDX) in the same amounts as the DX and $\mathrm{GH}$ groups. Arrows indicate the times of growth hormone treatment. Means with different uppercase letters $(A, B, C)$ are significantly different $(P<0.05)$ at the specific time points.

after day 28 because of health problems. All other calves were healthy up to the end of the study.

\section{Blood parameters}

Plasma growth hormone concentrations (Fig. 2) increased $(P<0 \cdot 05)$ in the GH and GHDX groups from day 3 to day 7 and then decreased $(P<0.05)$ up to day 28. Different treatments had different effects $(P<0 \cdot 001)$ on growth hormone concentrations with time; concentrations on day 7 were highest $(P<0 \cdot 01)$ in the $\mathrm{GH}$ group and were higher $(P<0 \cdot 01)$ in the GHDX group than in the CNTRL and DX groups. On day 14, concentrations were highest $(P<0 \cdot 01)$ in the $\mathrm{GH}$ group.

Plasma IGF-I concentrations (Fig. 3) increased $(P<0 \cdot 05)$ in the CNTRL group from day 14 to day 42 , increased $(P<0 \cdot 05)$ in the GH group from day 3 to day 42 , and increased in the GHDX group $(P<0.05)$ from day 3 to day 28 but thereafter decreased $(P<0 \cdot 05)$ to day 42 . Different treatments changed $(P<0 \cdot 001)$ IGF-I concentrations during the experimental period. Plasma IGF-I concentrations on days 7 and 14 were higher $(P<0 \cdot 05)$ in the GHDX group than in the CNTRL and DX groups, and on day 14 tended to be higher $(P<0 \cdot 1)$ in the GHDX group than in the GH group. On day 28 , IGF-I concentrations were higher $(P<0.05)$ in the GHDX group than in all other groups and were lower $(P<0 \cdot 05)$ in the DX than in the GH group. On day 42, concentrations were lowest $(P<0 \cdot 05)$ in the DX group and tended to be higher $(P<0 \cdot 1)$ in the GH than in the CNTRL groups.

Plasma IGFBP-1 concentrations (Fig. 4) increased $(P<0 \cdot 01)$ in the CNTRL and GH groups from day 3 to

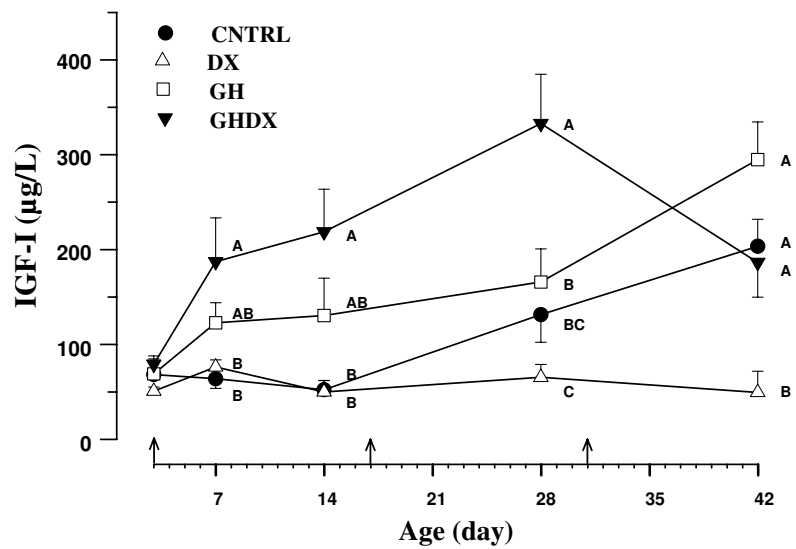

Figure 3 Plasma IGF-I concentrations on days 3, 7, 14, 28, 42 of life in control calves (CNTRL), calves treated with dexamethasone (30 $\mu \mathrm{g} / \mathrm{kg}$ body weight/day; DX), calves treated with growth hormone (500 mg/ 14 days; $\mathrm{GH}$ ), and calves treated with dexamethasone and growth hormone (GHDX) in the same amounts as the DX and GH groups. Arrows indicate the times of growth hormone treatment. Means with different uppercase letters $(\mathrm{A}, \mathrm{B}, \mathrm{C})$ are significantly different $(P<0.05)$ at the specific time points.

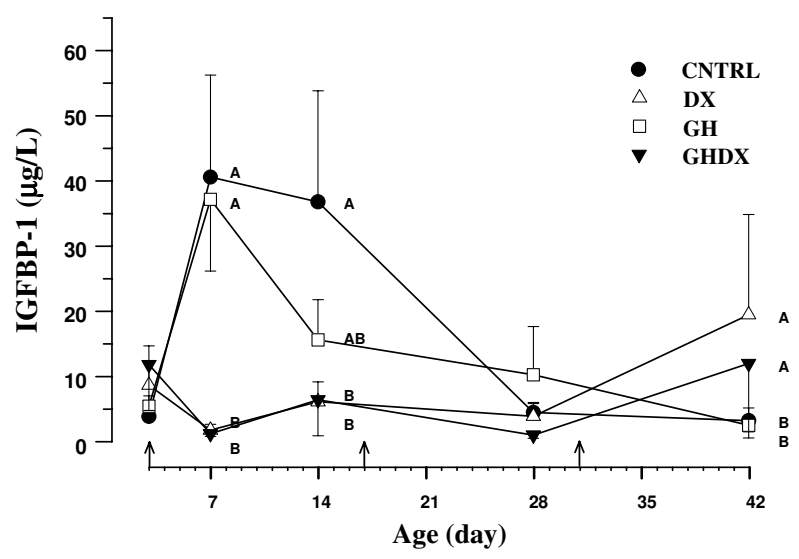

Figure 4 Plasma IGFBP-1 concentrations on days 3, 7, 14, 28, 42 of life in control calves (CNTRL), calves treated with dexamethasone (30 $\mu \mathrm{g} / \mathrm{kg}$ body weight/day; DX), calves treated with growth hormone (500 mg/14 days; $\mathrm{GH}$ ), and calves treated with dexamethasone and growth hormone (GHDX) in the same amounts as the DX and GH groups. Arrows indicate the times of growth hormone treatment. Means with different uppercase letters $(\mathrm{A}, \mathrm{B}, \mathrm{C})$ are significantly different $(P<0 \cdot 05)$ at the specific time points.

day 7 and then decreased $(P<0 \cdot 01)$ up to day 42 . Concentrations increased $(P<0 \cdot 05)$ in the DX and GHDX groups from day 28 to day 42. Different treatments changed $(P<0 \cdot 001)$ IGFBP-1 concentrations with time. Dexamethasone decreased IGFBP-1 concentrations on days 7 and 14 and increased IGFBP-1 concentrations on day 42 , whereas growth hormone had no effect on IGFBP-1 plasma concentrations.

Plasma IGFBP-3 (Fig. 5) concentrations increased $(P<0 \cdot 05)$ in the CNTRL and GH groups up to day 42 


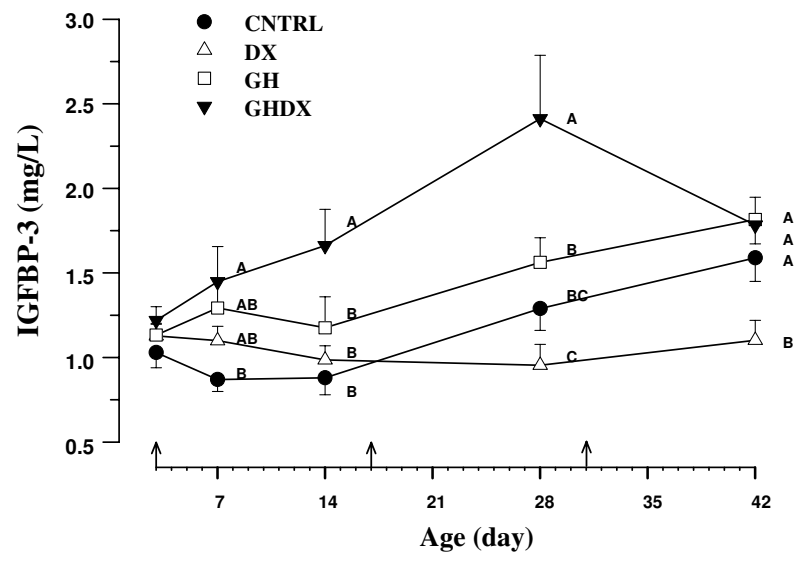

Figure 5 Plasma IGFBP-3 concentrations on days 3, 7, 14, 28, 42 of life in control calves (CNTRL), calves treated with dexamethasone (30 $\mu \mathrm{g} / \mathrm{kg}$ body weight/day; DX), calves treated with growth hormone (500 mg/14 days; $\mathrm{GH})$, and calves treated with dexamethasone and growth hormone (GHDX) in the same amounts as the DX and GH groups. Arrows indicate the times of growth hormone treatment. Means with different uppercase letters $(A, B, C)$ are significantly different $(P<0.05)$ at the specific time points.

and in the GHDX group up to day 28 , but decreased $(P<0 \cdot 05)$ from day 28 to day 42 . Different treatments changed $(P<0 \cdot 001)$ IGFBP-3 concentrations with time. Plasma concentrations on day 7 were higher $(P<0 \cdot 05)$ in the GHDX group than in the CNTRL group and on days 14 and 28 were higher $(P<0 \cdot 05)$ than in all other groups. On day 28 concentrations were higher $(P<0 \cdot 05)$ in the GH group than in the DX group and on day 42 concentrations were lowest $(P<0 \cdot 05)$ in the DX group.

\section{Abundance of IGF-I and GHR mRNA in the liver} (Table 1)

Abundance of GHR mRNA in liver tended to increase $(P<0 \cdot 1)$ in the CNTRL and GH groups from day 7 to day 42. Different treatments changed $(P<0 \cdot 05)$ GHR mRNA levels with time. On day 14 growth hormone and the combined dexamethasone and growth hormone treatment increased $(P<0.05)$ GHR mRNA levels. On day 42 , dexamethasone and the combined dexamethasone and growth hormone treatment decreased $(P<0.05)$ GHR mRNA levels.

Abundance of IGF-I mRNA levels in liver increased $(P<0 \cdot 05)$ in the CNTRL and GH groups from day 14 to day 42 and in the DX group from day 14 to day 28. Different treatments tended to change $(P<0 \cdot 1)$ IGF-I mRNA levels with time. On days 7 and 14 growth hormone increased $(P<0 \cdot 01)$ IGF-I mRNA levels and mRNA levels on day 14 were higher $(P<0.05)$ in the GHDX group than in the CNTRL and DX groups.
Dexamethasone decreased $(P<0 \cdot 05)$ IGF-I MRNA levels on day 42 .

\section{Correlations between tissue and blood parameters}

During the experimental period body weight correlated with hepatic mRNA abundance of IGF-I $(r=0.56$; $P<0.001)$ and GHR $(r=0 \cdot 44 ; P<0 \cdot 001)$ and with plasma concentrations of IGF-I $(r=0.52 ; \quad P<0.001)$, growth hormone $(r=-0 \cdot 29 ; \quad P<0 \cdot 01)$ IGFBP-1 $(r=-0 \cdot 28$; $P<0 \cdot 01)$ and IGFBP-3 $(r=0.56 ; P<0 \cdot 001)$. Levels of IGF-I mRNA in liver correlated with GHR mRNA levels $(r=0.73 ; P<0.001)$ and with plasma concentrations of IGF-I $\quad(r=0.62 ; \quad P<0 \cdot 001), \quad$ IGFBP-1 $\quad(r=-0 \cdot 28$; $P<0.01)$ and IGFBP-3 $(r=0.49 ; P<0 \cdot 01)$. Levels of GHR mRNA in liver correlated with plasma concentrations of IGF-I $(r=0.41 ; \quad P<0 \cdot 001), \quad$ IGFBP-1 $(r=-0 \cdot 29 ; P<0 \cdot 01)$ and IGFBP-3 $(r=0 \cdot 29 ; P<0 \cdot 01)$. Plasma concentrations of IGF-I correlated with plasma concentrations of IGFBP-1 $(r=-0.31 ; P<0.01)$ and IGFBP-3 $(r=0.85 ; P<0 \cdot 01)$. Plasma concentrations of IGFBP-1 correlated with plasma concentrations of IGFBP-3 $(r=-0 \cdot 29 ; P<0 \cdot 01)$. Almost the same pattern of correlations was seen in the CNTRL and GH group calves, whereas the number of correlations in the DX and GHDX groups were smaller (data not shown).

\section{Discussion}

The present study was performed to clarify the influence of dexamethasone on the somatotropic axis and the response of the hepatic IGF system to growth hormone treatment during the neonatal and early postnatal period in calves. We observed that the developmental increase in body weight in CNTRL calves was associated with an increase in plasma IGF-I and IGFBP-3 concentrations and with hepatic GHR and IGF-I mRNA levels, whereas plasma IGFBP-1 concentrations decreased. These findings support the general concept that the somatotropic axis is basically associated with growth performance during the early postnatal period (Kerr et al. 1991, Etherton \& Bauman 1998, Breier et al. 2000, Renaville et al. 2000). However, plasma IGF-I and IGFBP-3 concentrations as well as hepatic mRNA levels of GHR and IGF-I in CNTRL calves did not start to increase before day 14 , indicating a delayed response of the somatotropic axis in postnatal growth regulation. Our findings in calves support the view that the somatotropic axis in neonatal calves is not fully competent at birth and that the postnatal rise in IGF-I levels is delayed (Hammon \& Blum 1997, Nussbaum et al. 2002). The reasons for the low plasma concentrations of IGFBP-1 in all groups on day 3 are not known. The interval between feeding and blood sampling was the same for all groups and across sampling days. In addition, 
Table 1 Hepatic mRNA levels (arbitrary units) of GHR and IGF-I in calves treated with $0 \cdot 9 \% \mathrm{NaCl}$ (CNTRL), $30 \mu \mathrm{g} / \mathrm{kg}$ body weight dexamethasone (DX), $500 \mathrm{mg} / 14$ days growth hormone $(\mathrm{GH})$, and $30 \mu \mathrm{g} / \mathrm{kg}$ body weight dexamethasone and $500 \mathrm{mg} / 14$ days growth hormone (GHDX). Values are means \pm S.E.M. (pooled standard error). Main effects of dexamethasone $(\delta)$, growth hormone $(\phi)$ and dexamethasone $\times$ growth hormone $(\delta \times \phi)$ are shown

\begin{tabular}{|c|c|c|c|c|c|c|c|c|}
\hline & \multirow[b]{2}{*}{ Day } & \multicolumn{4}{|l|}{ Group } & \multicolumn{3}{|c|}{ Main effects ( $P$-values) } \\
\hline & & CNTRL & DX & $\mathrm{GH}$ & GHDX & $\delta$ & $\phi$ & $\delta \times \phi$ \\
\hline \multicolumn{9}{|c|}{ Parameter } \\
\hline \multirow{3}{*}{ GHR } & 14 & $0.73 \pm 0.09$ & $0 \cdot 82 \pm 0 \cdot 18$ & $1 \cdot 06 \pm 0 \cdot 19$ & $1 \cdot 37 \pm 0 \cdot 29$ & NS & $<0.05$ & $<0.05$ \\
\hline & 28 & $1 \cdot 7 \pm 0 \cdot 21$ & $1 \cdot 65 \pm 0 \cdot 18$ & $1 \cdot 62 \pm 0 \cdot 23$ & $1 \cdot 63 \pm 0 \cdot 15$ & NS & NS & NS \\
\hline & 42 & $2 \cdot 0 \pm 0 \cdot 31$ & $1 \cdot 05 \pm 0 \cdot 42$ & $1 \cdot 71 \pm 0 \cdot 14$ & $1 \cdot 06 \pm 0 \cdot 29$ & $<0 \cdot 001$ & NS & $<0.01$ \\
\hline \multirow{3}{*}{ IGF-I } & 14 & $0 \cdot 19 \pm 0 \cdot 04$ & $0 \cdot 2 \pm 0 \cdot 12$ & $0 \cdot 6 \pm 0 \cdot 26$ & $1 \cdot 64 \pm 0.44$ & NS & $<0.01$ & $<0.05$ \\
\hline & 28 & $1 \cdot 91 \pm 0.42$ & $1 \cdot 98 \pm 0.31$ & $1 \cdot 7 \pm 0.52$ & $1 \cdot 87 \pm 0.37$ & NS & NS & NS \\
\hline & 42 & $2 \cdot 27 \pm 0 \cdot 42$ & $1.91 \pm 0.79$ & $2 \cdot 95 \pm 0 \cdot 13$ & $1 \cdot 88 \pm 0.59$ & $<0.05$ & NS & NS \\
\hline
\end{tabular}

NS, not significant.

the order of sampling was uniformly balanced across treatments, therefore differences in IGFBP-1 are not attributable to short term nutritional status. Despite the lower IGFBP-1 in all groups on day 3, the plasma concentrations in the range of 5 to $50 \mathrm{mg} / \mathrm{l}$, measured in the present study, correspond to postprandial plasma concentrations in neonatal calves (Sauter et al. 2003).

Dexamethasone treatment depressed plasma concentrations of IGFBP-1 in the neonatal period, but did not depress mRNA levels of GHR and IGF-I and plasma concentrations of IGF-I and IGFBP-3 before day 42 . In the present study, chronic dexamethasone treatment failed to stimulate the somatotropic axis in the neonatal and early postnatal period, in contrast to recent findings in neonatal calves and pigs (Carroll 2001, Sauter et al. 2003). However, in these studies dexamethasone was injected immediately after birth and was administered only once (pigs; Carroll 2001) or for 4 days only (calves; Sauter et al. 2003). Obviously, the response of the somatotropic axis to dexamethasone treatment depends on age, dose, and duration of the administration (Bloomfield et al. 2001, Butler \& LeRoith 2001). In human hepatocytes shortterm dexamethasone treatment stimulated, whereas longterm treatment inhibited GHR gene expression (Vottero et al. 2003). The depression of the hepatic IGF system by dexamethasone on day 42 corresponds with findings in preterm infants (Bloomfield et al. 2001), during postnatal growth and in adults (Unterman \& Phillips 1985, Burrin et al. 1999), including cattle (Elsasser et al. 1997, Maciel et al. 2001). Dexamethasone treatment may also affect growth hormone clearance (plasma growth hormone concentrations were lower in the GHDX group than in the GH group on days 7 and 14) possibly by interfering with growth hormone binding proteins (Gabrielsson et al. 1995).

Plasma growth hormone concentrations increased in the GH group at the beginning of the study, but concen- trations did not remain elevated after day 14 of life. Although the blood sampling protocol did not permit a detailed evaluation of growth hormone status, the lack of plasma growth hormone responses in the GH and GHDX groups from day 28 onwards was unexpected (Holzer et al. 2000). The clearance rate of growth hormone may increase with age, because plasma growth hormone concentrations were elevated on day 14 of life (11 days after the first injection of growth hormone), but not on days 28 and 42 (11 days after the second and third injections of growth hormone respectively). The postnatal maturation of the somatotropic axis greatly depends on the competency of hepatic GHRs, which are low during fetal development and gradually increase after birth (Badinga et al. 1991, Min et al. 1999, Sauter et al. 2003). Growth hormone treatment up-regulates hepatic growth hormone binding sites in sheep, but not in lambs (Sauerwein et al. 1991, Min et al. 1999). Although growth hormone stimulated hepatic IGF-I mRNA levels up to day 14 in our study, plasma concentrations of IGF-I in the GH group did not increase before day 42 in our study, as is known for cattle (Elsasser et al. 1989, Holzer et al. 2000, Smith et al. 2002). Because hepatic IGF-I is the main source for circulating IGF-I in cattle (Pfaffl et al. 1998, Cordano et al. 2000), it may take some time before the mature IGF-I peptide is delivered to the circulation.

Most impressively, the combined growth hormone and dexamethasone treatment markedly stimulated the somatotropic axis up to day 28 of life. The IGF-I response to growth hormone treatment depends on the degree of maturation of the somatotropic axis and increases with age and nutrient intake (Breier et al. 2000, Holzer et al. 2000). Our findings suggest that dexamethasone greatly increases the hepatic IGF-I response to growth hormone treatment in the neonatal period. Studies with porcine hepatocytes, too, showed increased responsiveness of IGF-I mRNA to growth hormone after dexamethasone treatment 
(Brameld et al. 1995), but in rats dexamethasone inhibited the IGF-I response to growth hormone (Luo \& Murphy 1989, Beauloye et al. 1999). Because plasma insulin concentrations were elevated in the GHDX group (Hammon et al. 2003), insulin might, in part, have stimulated hepatic IGF-I production, as seen in rats and cows (Böni-Schnetzler et al. 1991, McGuire et al. 1995). Furthermore, elevated plasma IGF-I may result from reduced clearance rates due to increased IGFBP-3 and decreased IGFBP-1 plasma concentrations, which are closely associated with IGF-I and insulin concentrations. The IGFBP-3 retains IGF-I in the circulation by binding with the acid-labile subunit, whereas IGFBP-1 is able to leave the circulation (Clemmons 1997). The enhanced response of the somatotropic axis to growth hormone following dexamethasone treatment was abolished at the end of the study on day 42. Therefore, the enhanced growth hormone effects on the hepatic IGF system due to dexamethasone treatment might be age-dependent or might be a consequence of the chronic dexamethasone treatment.

Most parameters of the somatotropic axis measured in this study were closely related to body weight, as expected. However, contrary to chronic dexamethasone treatment in preterm infants and during postnatal growth, dexamethasone treatment in our study did not affect body weight gain before day 28 after birth (Spencer 1985, Bloomfield et al. 2001, Newnham \& Moss 2001, Renaville et al. 2002). The lack of effects on growth performance during the first month of life in the DX group was associated with unresponsiveness of the somatotropic axis to dexamethasone. In neonatal pigs, a single dose of dexamethasone treatment after birth improved postnatal growth performance (Carroll 2001, Gaines et al. 2002), whereas chronic dexamethasone administration reduced growth rates (Burrin et al. 1999). Based on this information, the effects of glucocorticoids on growth performance in the neonatal period seem to depend on dose and duration of glucocorticoid administration, in accordance with studies in preterm infants (Bloomfield et al. 2001). Growth hormone treatment had no significant effect on body weight up to 6 weeks, but average daily gain was improved in the GH group when calves were studied during the first 2 months of life (Hammon \& Donkin 2002). Previous studies in veal calves that were administered growth hormone daily up to the time of slaughter (age about 140 days) could not demonstrate any marked growth enhancement either (Ceppi \& Blum 1994), indicating that it takes a long period of time before growing cattle become fully responsive to growth hormone. Administration of slow-release growth hormone to about 180-day-old calves resulted in a more distinct growth stimulation (Holzer et al. 2000). The enhanced hepatic IGF response to growth hormone treatment by dexamethasone failed to stimulate growth performance during the first month of life. Furthermore, the disappear- ance of stimulatory effects on the somatotropic axis after day 28 in the GHDX group was combined with a cessation of body weight gain.

In conclusion, dexamethasone administration improved the response of the IGF system to growth hormone treatment during the first month of life, but neither growth hormone nor dexamethasone alone or in combination stimulated postnatal growth during this time period. Dexamethasone and the growth hormone/ dexamethasone combination depressed body weight gain and the somatotropic axis after day 28 of life, indicating that the response of the somatotropic axis to dexamethasone treatment in calves depends on age or at least on the duration of dexamethasone treatment.

\section{Acknowledgements}

Many thanks are due to Mike Grott and his team at the Purdue Dairy Research and Education Centre for daily calf care. Thanks are also extended to Juan Carlos Velez, Stacy Crowder and Jon Townsend for assistance with liver biopsy sampling and Tracy Wiegand for technical assistance with metabolite assays.

\section{Funding}

This work was supported in part by funds from the Indiana Agricultural Research as part of the North Central Regional project NC-1009. H M Hammon was supported by the University of Berne during his residence at Purdue University. There is no conflict of interest that would prejudice the impartiality of this work.

\section{References}

Badinga L, Collier RJ, Thatcher WW, Wilcox CJ, Head HH \& Bazer FW 1991 Ontogeny of hepatic bovine growth hormone receptors in cattle. Journal of Animal Science 69 1925-1934.

Beauloye V, Ketelslegers JM, Moreau B \& Thissen JP 1999 Dexamethasone inhibits both growth hormone $(\mathrm{GH})$-induction of insulin-like growth factor-I (IGF-I) mRNA and GH receptor (GHR) mRNA levels in rat primary cultured hepatocytes. Growth Hormone and IGF Research 9 205-211.

Bloomfield FH, Knight DB, Breier BH \& Harding JE 2001 Growth restriction in dexamethasone-treated preterm infants may be mediated by reduced IGF-I and IGFBP-3 plasma concentrations. Clinical Endocrinology 54 235-242.

Böni-Schnetzler M, Schmid C, Meier PJ \& Froesch ER 1991 Insulin regulates insulin-like growth factor I mRNA in rat hepatocytes. American Journal of Physiology 260 E846-E851.

Brameld JM, Weller PA, Saunders JC, Buttery PJ \& Gilmour RS 1995 Hormonal control of insulin-like growth factor-I and growth hormone receptor mRNA expression by porcine hepatocytes in culture. Journal of Endocrinology 146 239-245.

Breier BH, Oliver MH \& Gallaher BW 2000 Regulation of growth and metabolism during postnatal development. In Ruminant Physiology: Digestion, Metabolism, Growth and Reproduction, pp 187-204. Ed PB Cronjé. New York: CABI Publishing. 
Burrin DG, Wester TJ, Davis TA, Fiorotto ML \& Chang X 1999 Dexamethasone inhibits small intestinal growth via increased protein catabolism in neonatal pigs. American Journal of Physiology 276 E269-E277.

Butler AA \& Le Roith D 2001 Control of growth by the somatotropic axis: growth hormone and the insulin-like growth factors have related and independent roles. Annual Review of Physiology 63 141-164.

Carroll JA 2001 Dexamethasone treatment at birth enhances neonatal growth in swine. Domestic Animal Endocrinology 21 97-109.

Ceppi A \& Blum JW 1994 Effects of growth hormone on growth performance, haematology, metabolites and hormones in iron deficient veal calves. Journal of Veterinary Medicine. Series A, Physiology, Pathology, Clinical Medicine 41 443-458.

Clemmons DR 1997 Insulin-like growth factor binding proteins and their role in controlling IGF actions. Cytokine and Growth Factor Reviews 8 45-62.

Cordano P, Hammon HM, Morel C, Zurbriggen A \& Blum JW 2000 mRNA of insulin-like growth factor (IGF) quantification and presence of IGF binding proteins, and receptors for growth hormone, IGF-I and insulin, determined by reverse transcribed polymerase chain reaction, in the liver of growing and mature male cattle. Domestic Animal Endocrinology 19 191-208.

Donkin SS, McNall AD, Swencki BS, Peters JL \& Etherton TD 1996 The growth hormone dependent decrease in hepatic fatty acid synthase mRNA is the result of a decrease in gene transcription. Journal of Molecular Endocrinology 16 151-158.

Elsasser TH, Rumsay TS \& Hammond AC 1989 Influence of diet on basal and growth hormone-stimulated plasma concentrations of IGF-I in beef cattle. Journal of Animal Science 67 128-141.

Elsasser TH, Kahl S, Steele NC \& Rumsey TS 1997 Nutritional modulation of somatotropic axis-cytokine relationships in cattle: a brief review. Comparative Biochemistry and Physiology A. Molecular and Integrative Physiology 116 209-221.

Etherton TD \& Bauman DE 1998 Biology of somatotropin in growth and lactation of domestic animals. Physiological Reviews $\mathbf{7 8}$ 745-761.

Gabrielsson BG, Carmignac DF, Flavell DM \& Robinson IC 1995 Steroid regulation of growth hormone $(\mathrm{GH})$ receptor and $\mathrm{GH}-$ binding protein messenger ribonucleic acid in the rat. Endocrinology 136 209-217.

Gaines AM, Carroll JA, Allee GL \& Yi GF 2002 Pre- and postweaning performance of pigs injected with dexamethasone at birth. Journal of Animal Science 80 2255-2262.

Gluckman PD, Sizonenko SV \& Bassett NS 1999 The transition from fetus to neonate - an endocrine perspective. Acta Paediatrica Scandinavica Supplementum 428 7-11.

Greenfield RB, Cecava MJ \& Donkin SS 2000 Changes in mRNA expression for gluconeogenic enzymes in liver of dairy cattle during transition to lactation. Journal of Dairy Science 83 1228-1236.

Hammon H \& Blum JW 1997 The somatotropic axis in neonatal calves can be modulated by nutrition, growth hormone, and long-R3-IGF-I. American Journal of Physiology 273 E130-E138.

Hammon H \& Blum JW 1998 Metabolic and endocrine traits of neonatal calves are influenced by feeding colostrum for different durations or only milk replacer. Journal of Nutrition 128 624-632.

Hammon HM \& Donkin SS 2002 Growth hormone influences growth performance, but does not affect gluconeogenesis from lactate or propionate in 60-day-old veal calves. Journal of Dairy Science 85 (Suppl 1) 337.

Hammon HM, Blum JW \& Donkin SS 2003 Effects of dexamethasone (DEXA) and growth hormone (ST) on glucose production in calves. Journal of Animal Science 81 (Suppl 1) 310.

Hennies M \& Sauerwein H 2003 Purification of bovine IGFBP-3 and the development of an enzyme immunoassay for the protein. Journal of Immunological Methods 281 9-15.
Holzer Z, Aharoni Y, Brosh A, Orlov A \& Buonomo F 2000 The influence of recombinant bovine somatotropin on dietary energy level-related growth of Holstein-Freisian bull calves. Journal of Animal Science 78 621-628.

Kaufhold JN, Hammon HM, Bruckmaier RM, Breier BH \& Blum JW 2000 Postprandial metabolism and endocrine status in veal calves fed at different feeding frequencies. Journal of Dairy Science $\mathbf{8 3}$ 2480-2490.

Kerr DE, Laarveld B, Fehr MI \& Manns JG 1991 Profiles of serum IGF-I concentrations in calves from birth to eighteen months of age and in cows throughout the lactation cycle. Canadian Journal of Animal Science 71 695-705.

Kobayashi Y, Boyd CK, Bracken CJ, Lamberson WR, Keisler DH \& Lucy MC 1999 Reduced growth hormone receptor (GHR) messenger ribonucleic acid in liver of periparturient cattle is caused by specific down-regulation of GHR 1A that is associated with decreased insulin-like growth factor I. Endocrinology $\mathbf{1 4 0}$ 3947-3954.

Li J, Owens JA, Owens PC, Saunders JC, Fowden AL \& Gilmour RS 1996 The ontogeny of hepatic growth hormone receptor and insulin-like growth factor I gene expression in the sheep during late gestation: developmental regulation by cortisol. Endocrinology 137 $1650-1657$.

Luo J \& Murphy LJ 1989 Dexamethasone inhibits growth hormone induction of insulin-like growth factor-I (IGF-I) messenger ribonucleic acid (mRNA) in hypophysectomized rats and reduced IGF-I mRNA abundance in the intact rat. Endocrinology $\mathbf{1 2 5}$ 165-171.

McGuire MA, Dwyer DA, Harrell RJ \& Bauman DE 1995 Insulin regulates circulating insulin-like growth factors and some of their binding proteins in lactating cows. American Journal of Physiology 269 E723-E730.

Maciel SM, Chamberlain CS, Wettemann RP \& Spicer LJ 2001 Dexamethasone influences endocrine and ovarian function in dairy cattle. Journal of Dairy Science 84 1998-2009.

Min SH, Mackenzie DDS, Breier BH, McCutcheon SN \& Gluckman PD 1999 Ontogeny of IGF-I responsiveness to bGH in young lambs. Domestic Animal Endocrinology 17 409-419.

Newnham JP \& Moss TJ 2001 Antenatal glucocorticoids and growth: single versus multiple doses in animal and human studies. Seminars in Neonatology 6 285-292.

Nussbaum A, Schiessler G, Hammon HM \& Blum JW 2002 Growth performance and metabolic and endocrine traits in calves pair-fed by bucket or by automate starting in the neonatal period. Journal of Animal Science 80 1545-1555.

Pfaffl M, Meyer HHD \& Sauerwein H 1998 Quantification of insulin-like growth factor-I (IGF-I) mRNA: development and validation of an internally standardised competitive reverse transcription-polymerase chain reaction. Experimental and Clinical Endocrinology and Diabetes 106 506-513.

Renaville R, Van Einaime C, Breier BH, Vleurick L, Bertozzi C, Gengler N, Hornick JL, Parmentier I, Istasse L, Haezebroeck V, Massart S \& Portetelle D 2000 Feed restriction in young bulls alters the onset of puberty in relationship with plasma insulin-like growth factor-I (IGF-I) and IGF-binding proteins. Domestic Animal Endocrinology 18 165-176.

Renaville R, Hammadi M \& Portetelle D 2002 Role of the somatotropic axis in the mammalian metabolism. Domestic Animal Endocrinology 23 351-360.

SAS 1995 SAS/STAT User Guide (release 6•11). SAS Inst. Inc., Cary, NC.

Sauerwein H, Breier BH, Bass JJ \& Gluckman PD 1991 Chronic treatment with bovine growth hormone upregulates high-affinity hepatic somatotropic receptors in sheep. Acta Endocrinologica 124 307-313.

Sauter SN, Ontsouka E, Roffler B, Zbinden Y, Philipona C, Pfaffl M, Breier BH, Blum JW \& Hammon HM 2003 Effects of 
dexamethasone and colostrum intake on the somatotropic axis in neonatal calves. American Journal of Physiology 285 E252-E261.

Smith JM, Van Amburgh ME, Díaz MC, Lucy MC \& Bauman DE 2002 Effects of nutrient intake on the development of thesomatotropic axis and its responsiveness to GH in Holstein bull calves. Journal of Animal Science 80 1528-1537.

Spencer GSG 1985 Hormonal systems regulating growth. Livestock Production Science 12 31-46.

Unterman TG \& Phillips LS 1985 Glucocorticoid effects on somatomedins and somatomedin inhibitors. Journal of Clinical Endocrinology and Metabolism 61 618-626.

Vandehaar MJ, Sharma BK \& Fogwell RL 1995 Effects of dietary energy restriction on expression of insulin-like growth factor-I in liver and corpus luteum of heifers. Journal of Dairy Science $\mathbf{7 8}$ 832-841.

Vottero A, Kimchi-Sarfaty C, Kratzsch J, Chrousos GP \& Hochberg Z 2003 Transcriptional and translational regulation of the splicing isoforms of the growth hormone receptor by glucocorticoids.

Hormone and Metabolic Research 35 7-12.

Received in final form 7 August 2003

Accepted 20 August 2003

Made available online as an

Accepted Preprint 26 August 2003 